\title{
Sensitive detection and quantification of SARS-CoV-2 by multiplex droplet digital RT-PCR
}

\author{
Remco de Kock ${ }^{1,2,3}$ (1) $\cdot$ Mieke Baselmans ${ }^{1} \cdot$ Volkher Scharnhorst $^{1,2,3} \cdot$ Birgit Deiman $^{1,2,3}$
}

Received: 15 September 2020 / Accepted: 14 October 2020 / Published online: 26 October 2020

(C) The Author(s) 2020

\begin{abstract}
The purpose of this study is to develop a one-step droplet digital RT-PCR (RT-ddPCR) multiplex assay that allows for sensitive quantification of SARS-CoV-2 RNA with respect to human-derived RNA and could be used for screening and monitoring of Covid-19 patients. A one-step RT-ddPCR multiplex assay was developed for simultaneous detection of SARS-CoV-2 E, RdRp and $N$ viral RNA, and human Rpp30 DNA and GUSB mRNA, for internal nucleic acid (NA) extraction and RT-PCR control. Dilution series of viral RNA transcripts were prepared in water and total NA extract of Covid-19-negative patients. As reference assay, an $E$-GUSB duplex RT-PCR was used. GUSB mRNA detection was used to set validity criteria to assure viral RNA and RT-PCR assay quality and to enable quantification of SARS-CoV-2 RNA. In a background of at least 100 GUSB mRNA copies, 5 copies of viral RNA are reliably detectable and 10 copies viral RNA copies are reliably quantifiable. It was found that assay sensitivity of the RT-ddPCR was not affected by the total NA background while assay sensitivity of the gold standard RT-PCR assay is drastically decreased when SARS-CoV-2 copies were detected in a background of total NA extract compared with water. The present study describes a robust and sensitive one-step ddRT-PCR multiplex assay for reliable quantification of SARS-CoV2 RNA. By determining the fractional abundance of viral RNA with respect to a human housekeeping gene, viral loads from different samples can be compared, what could be used to investigate the infectiveness and to monitor Covid-19 patients.
\end{abstract}

Keywords SARS-CoV-2 $\cdot$ ddPCR $\cdot$ Multiplex $\cdot$ RT-PCR $\cdot$ Quantification $\cdot$ Monitoring

\section{Introduction}

The outbreak of Covid-19 caused by SARS-CoV-2 has spread worldwide. Up to now, over 35 million confirmed cases have been reported. The USA, Brazil, and India are the most affected countries with the highest mortality rates due to Covid-19 [1].

The gold standard for the detection of SARS-CoV-2 is based on real-time reverse transcriptase PCR (RT-PCR). In

Remco de Kock

Remco.d.kock@catharinaziekenhuis.nl

1 Clinical Laboratory, Catharina Hospital Eindhoven, Eindhoven, The Netherlands

2 Institute for Complex Molecular Systems and Department of Biomedical Engineering, Laboratory of Chemical Biology, Eindhoven University of Technology, Eindhoven, The Netherlands

3 Expert Center Clinical Chemistry Eindhoven, Eindhoven, The Netherlands the Netherlands, the detection of the envelope $(E)$ gene, followed by confirmatory testing of the RNA-dependent RNA polymerase (RdRp) gene, is recommended [2]. Another approach is to detect the nucleocapsid $(N)$ gene and to use an open reading frame $1 \mathrm{a} / \mathrm{b}(O R F 1 b)$ gene or $E$ gene assay as a confirmatory test [3]. In addition, to improve assay sensitivity, other studies have been focusing on the detection of $N, E$, or $O R F 1 b$ using droplet digital polymerase chain reaction (ddPCR) [4-7].

As the RNA genome of SARS-CoV-2 mutates during virus replication, false negative results could be obtained due to the loss of primer or probe binding [8,9]. By using multiplex assays, targeting various SARS-CoV-2 genes, the chance of missing a positive sample in this way is reduced.

The amount and quality of viral RNA in the patient sample is an important factor for reliable virus detection. Also, most assays do not include a patient-derived internal RNA control for the reverse transcriptase step, which is a critical step in viral RNA detection. The inclusion of a patient-derived internal RNA control would enable for quality control of the (viral) RNA in the patient sample and the RT-PCR. 
Finally, quantification of the SARS-CoV-2 viral load becomes more and more important to distinguish positive patients who are infectious from positive patients with only residual viral RNA who are probably not infectious anymore (viral shedding) [10] and for monitoring Covid-19 patients during treatment.

The goal of this study is to develop a sensitive one-step droplet digital RT-PCR (RT-ddPCR) multiplex assay for simultaneous detection of multiple SARS-CoV-2 genes $\mathrm{N}$ (NI+ $N 2), E$, and $R d R p$, including the detection of patient-derived mRNA of a housekeeping gene to assure sample and assay quality and to enable quantification of viral RNA.

\section{Methods}

\section{Samples}

As reference standard, the Wuhan Coronavirus 2019 E gene control (EVAg, European Virus Archive Global, France), an in vitro transcript $(100,000$ copies $/ \mathrm{mL})$, was used directly for amplification. Additionally, transcript RNA of the $E, N$, $O R F 1 a b, R d R p$, and $S$ gene (all 200,000 copies/mL), extracted from the Exact Diagnostics SARS-CoV-2 Standard (EDx, Exact Diagnostics, Texas, USA) using the MP24 Total NA isolation Kit, on the MagNA Pure 24 system (Roche Diagnostics, Rotkreuz, Switzerland), was used for amplification.

Dilution series of the reference standards were prepared in nuclease-free water and in remnant total nucleic acid (NA) MagNaPure 24 extract from nasopharyngeal swabs of Covid-19-negative patients, to obtain an input of 5-500 copies per reaction for the EVAg control and 2.5-1000 copies per reaction for the EDx control.

\section{One-step reverse transcriptase real-time PCR}

The one-step reverse transcriptase reaction for the detection of the $E$ gene was performed in a $25 \mu \mathrm{L}$ reaction volume as described previously [2]. The assay was also performed in a $10 \mu \mathrm{L}$ reaction volume, consisting of $5 \mu \mathrm{L} 2 \times$ reaction buffer, $0.16 \mu \mathrm{L}$ of a $50 \mathrm{mM}$ magnesium sulfate solution and $0.40 \mu \mathrm{L}$ of SuperScript ${ }^{\mathrm{TM}}$ III RT/Platinum ${ }^{\mathrm{TM}}$ Taq Mix (all provided by the SuperScript ${ }^{\mathrm{TM}}$ III One-Step RT-PCR with Platinum ${ }^{\mathrm{TM}}$ Taq Polymerase, Invitrogen, USA), $400 \mathrm{nM}$ forward primer, $400 \mathrm{nM}$ reverse primer, $200 \mathrm{nM}$ probe (primers and probe provided by TIB MolBiol, Berlin, Germany), $0.4 \mu \mathrm{g}$ of nonacetylated bovine serum albumin (Ultrapure ${ }^{\mathrm{TM}} \mathrm{BSA}$, Invitrogen, USA), and $2 \mu \mathrm{L}$ of RNA.

The $E$-GUSB duplex RT-PCR was performed in a $25 \mu \mathrm{L}$ and $10 \mu \mathrm{L}$ reaction volume as described above, with the addition of $1.25 \mu \mathrm{L}$ and $0.5 \mu \mathrm{L}$ of the GUSB Gene Expression assay (Bio-Rad Laboratories, Hercules, CA), respectively.
All assays were performed on the LightCycler 480 II system (Roche Diagnostics) using the following cycling conditions: $10 \mathrm{~min}$ at $55^{\circ} \mathrm{C}$ for reverse transcription, followed by 3 min at $95{ }^{\circ} \mathrm{C}$, continuing with $15 \mathrm{~s}$ at $95^{\circ} \mathrm{C}$, and $30 \mathrm{~s}$ at $58{ }^{\circ} \mathrm{C}$.

\section{One-step reverse transcriptase droplet digital PCR multiplex}

The ddPCR multiplex assay allows for the simultaneous detection of $E, R d R p, N(N 1+N 2), R p p 30$, and GUSB. For each assay, a reaction mixture of $22 \mu \mathrm{L}$ was prepared with $17 \mu \mathrm{L}$ amplification mix and $5 \mu \mathrm{L}$ RNA extract. The amplification mix, based on the one-step RT-ddPCR advanced kit for probes (Bio-Rad Laboratories), consisted of $5.5 \mu \mathrm{L}$ Supermix, $2.2 \mu \mathrm{L}$ reverse transcriptase, and $1.1 \mu \mathrm{L} 300 \mathrm{mM}$ DTT (Bio-Rad Laboratories). The primers and probes for the detection of $E$ and SARS-CoV-2 specific $R d R p$ were described previously [2] except for the $E$ reverse primer, as using this primer, false positive reactions were obtained. For $E$, $450 \mathrm{nmol}$ forward primer [2], $450 \mathrm{nmol}$ in-house reverse primer (5'-GGTTTTACAAGACTCACGTTAACA-3') (TIB MolBiol), and 250 nmol HEX-labeled and 250 nmol FAMlabeled probe [2] (Integrated DNA technologies, Coralville, USA) were added; for $R d R p, 900 \mathrm{nmol}$ forward and reverse primers and $250 \mathrm{nmol}$ probe [2] were added; for $N, 1.0 \mu \mathrm{L}$ 2019-nCov CDC ddPCR Triplex Probe assay (Bio-Rad Laboratories) was added and $1.0 \mu \mathrm{L}$ of GUSB assay (BioRad Laboratories) was added.

The QX200 Droplet Digital PCR System (Bio-Rad Laboratories) was used for the quantification of SARS-CoV2 RNA. For droplet generation, $20 \mu \mathrm{L}$ reaction mix was used and the droplets were transferred to a 96-well plate. Samples were amplified in the C1000 Touch Thermal Cycler (Bio-Rad Laboratories) according to following protocol: $50{ }^{\circ} \mathrm{C}$ for $60 \mathrm{~min}$ (reverse transcription), $95^{\circ} \mathrm{C}$ for $10 \mathrm{~min}$ (enzyme activation), 40 cycles of $95{ }^{\circ} \mathrm{C}$ for $30 \mathrm{~s}$ (denaturation) and $55^{\circ} \mathrm{C}$ for $60 \mathrm{~s}$ (annealing), and $98{ }^{\circ} \mathrm{C}$ for $10 \mathrm{~min}$ (enzyme deactivation). Data were analyzed using QuantaSoft version 1.7.4.0917 (Bio-Rad Laboratories).

\section{Results}

Recently, a commercial RT-ddPCR assay, targeting two highly conserved regions of the SARS-CoV-2 $N$ gene became available (2019-nCoV CDC ddPCR Triplex Probe assay, Bio-Rad Laboratories). This assay also includes an internal control for the detection of patient-derived Rpp30 as internal DNA control for the PCR step. Based on this assay, a multiplex one-step RT-ddPCR test was developed for the detection of the $E, R d R p$, and $N(N 1+N 2)$ gene. In addition, primers and probes for the detection of patient-derived GUSB mRNA were 
added as reverse transcriptase control. The multiplex was tested on the EDx reference standard, including transcripts of $E$, $R d R p$, and $N$ and human genomic total nucleic acid (NA). For each SARS-CoV-2 target, a distinct cluster was identified in the two-dimensional scatterplot (Fig. 1a). For a reproducibility analysis, 5 replicates of the EDx standard were tested and quantified, showing that the SARS-CoV-2 concentrations were all in the same order of magnitude and in agreement with the input used (Table 1).

\section{Assay sensitivity}

To determine assay sensitivity of the SARS-CoV-2 RTddPCR multiplex assay, the previously described one-step reverse transcriptase RT-PCR targeting the $E$ gene [2] was set up and used as reference assay. To ensure the correct performance of this reference assay, a dilution series of the EVAg standard was tested, showing that the $E$ target could be detected down to an input of 5 copies per reaction (Fig. 2a), which is in agreement with the performance of this assay as described previously [2].

To reflect a more realistic clinical setting, a comparable dilution series of the EVAg standard was prepared in total NA extract obtained from nasopharyngeal swabs of Covid19-negative patients. Strikingly, for the EVAg standard diluted in NA extract, 5 SARS-CoV-2 copies per reaction was no longer detectable and only 1 out of 4 reactions was tested positive, suggesting loss of sensitivity when compared to the EVAg standard diluted in water (Fig. 2a and b).

As this reference assay does not include the detection of a patient-derived internal control, a duplex reaction was developed combining the $E$ gene reference assay [2] with the GUSB assay (Bio-Rad Laboratories). The sensitivity of the $E-G U S B$ duplex RT-PCR was tested, using the previously described dilution series of the EVAg standard in water (Fig. 2a). Results show that using the $E-G U S B$ duplex RT-PCR, an input of 5 copies per reaction is still detectable, suggesting no loss of assay sensitivity compared with the $E$ gene reference assay [2].

Next, both the $E$ gene reference assay [2] and the $E-G U S B$ duplex assay were tested using a dilution series in water of the EDx standard, including GUSB mRNA. Again, no loss of sensitivity was observed when comparing the performance of the $E$ gene reference assay and the $E-G U S B$ duplex assay (Fig. 3a; Table 2). For both assays, using an input of 10 SARS-CoV-2 EDx copies per reaction, $100 \%$ was tested positive $(n=2)$, while using an input of 5 SARS-CoV-2 EDx copies per reaction, $50 \%$ tested positive $(n=4$; Fig. $3 \mathrm{a}$ and c; Table 2). EDx copies are not identical to EVAg copies as the EVAg standard is used directly in amplification, while the

\section{SARS-CoV-2 RT-ddPCR Multiplex Assay}

a

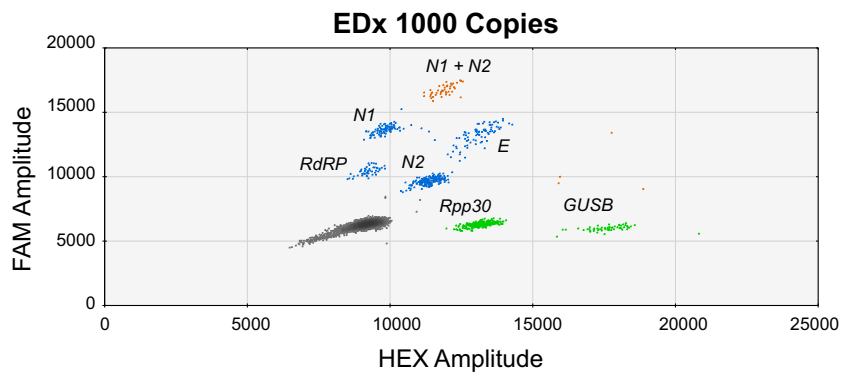

C

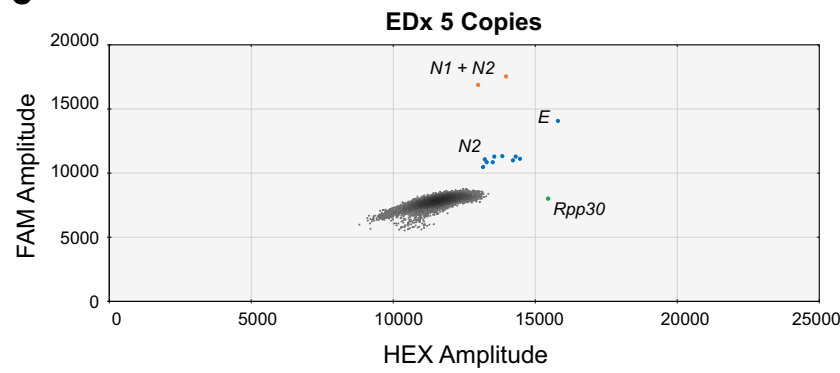

Fig. 1 Two-dimensional scatterplots of the SARS-CoV-2 RT-ddPCR multiplex assay targeting $N, E$, and $R d R p$ (FAM). Rpp30 is included as internal DNA control and GUSB as internal reverse transcriptase control (HEX). a Undiluted EDx standard with 1000 SARS-CoV-2 copies per reaction $(n=1)$. b Total NA extract from nasopharyngeal swabs from b

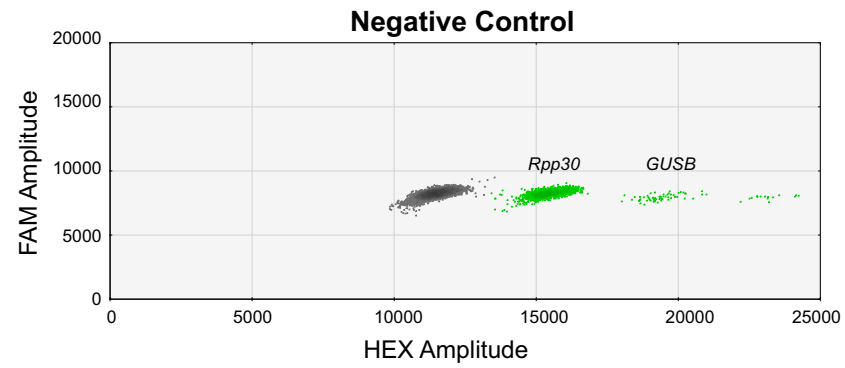

d

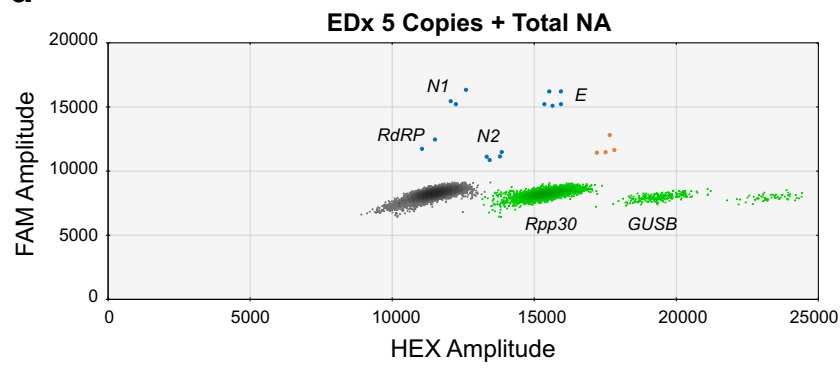

Covid-19-negative patients. c EDx standard, diluted in water, with 5 SARS-CoV-2 copies per reaction $(n=4)$. $\mathbf{d}$ EDx standard, diluted in total NA extract from Covid-19-negative patients, with 5 SARS-CoV-2 copies per reaction $(n=4)$ 
Table 1 Validation samples tested with the SARS-CoV-2 RT-ddPCR multiplex assay

\begin{tabular}{llcc}
\hline Sample & SARS-CoV-2 (copies/reaction) & Rpp30 (copies/reaction) & GUSB (copies/reaction) \\
\hline Positive control 1 & $1018(946-1090)$ & $488(438-536)$ & $116(92-140)$ \\
Positive control 2 & $806(732-882)$ & $308(262-356)$ & $62(42-84)$ \\
Positive control 3 & $868(796-942)$ & $472(420-526)$ & $64(46-86)$ \\
Positive control 4 & $848(776-922)$ & $430(378-482)$ & $74(54-98)$ \\
Positive control 5 & $896(816-978)$ & $452(396-510)$ & $110(84-140)$ \\
Negative control 1 & ND & $512(450-574)$ & $370(316-422)$ \\
Negative control 2 & ND & $1580(1460-1700)$ & $14(6-30)$ \\
Negative control 3 & ND & $1800(1700-1920)$ & $108(84-134)$ \\
Negative control 4 & ND & $11,660(11,320-12,000)$ & $466(406-526)$ \\
Negative control 5 & ND & $5000(4820-5200)$ & $128(100-158)$ \\
\hline
\end{tabular}

The undiluted EDx standard was used as positive control and total NA extract from remnant nasopharyngeal swabs from Covid-19-negative patients as negative control

$N D$ not detected, FA fractional abundance of viral RNA calculated with respect to the GUSB concentration

EDx standard requires extraction, like patient samples, during which some RNA will be lost. Again, when using dilution series of the EDx standard prepared in total NA extract from Covid-19-negative patients, a serious loss of sensitivity was observed for both the $E$ gene reference assay and the $E-G U S B$ duplex assay, as 5 and 10 SARS-CoV-2 EDx copies per reaction were no longer reliably detectable (Fig. $3 \mathrm{~b}$ and d; Table 2). The E-GUSB duplex RT-PCR was further used as reference assay to investigate the assay performance of the SARS-CoV-2 RT-ddPCR multiplex assay.

The same EDx dilution series, in water and in total NA extract of Covid-19-negative patients, were used to investigate the sensitivity of the SARS-CoV-2 RT-ddPCR multiplex assay. Using 5 SARS-CoV-2 copies per reaction of the EDx standard diluted in water, SARS-CoV-2 RNA could be detected ( $n=4$; Fig. 1c; Table 2), which is comparable with the assay sensitivity of the E-GUSB duplex RT-PCR. Fortunately, when using the EDx standard diluted in total NA extract from Covid-19-negative patients, the SARSCoV-2 multiplex RT-ddPCR assay could again detect 5
SARS-CoV-2 copies per reaction ( $n=4$; Fig. $1 \mathrm{~d}$; Table 2 ). For each dilution, in water or total NA extract, the detected SARS-CoV-2 concentration was in the same order of magnitude (Fig. 4; Table 2), indicating that the sensitivity of the RTddPCR multiplex assay is not affected by the total NA extract. In addition, in the presence of total NA extract, the SARSCoV-2 multiplex RT-ddPCR assay is approximately 10-fold more sensitive than the $E-G U S B$ duplex RT-PCR assay. The limit of detection (LoD) of the SARS-CoV-2 multiplex RTddPCR assay is estimated to be 5 copies per reaction.

\section{Quantification of viral RNA}

To correct for the differences in RNA yield and quality obtained during sample collection and differences in efficiency of the RT-ddPCR, quantification of the viral load was performed relative to the patient-derived GUSB mRNA (fractional abundance, FA). For the undiluted EDx standard, a reproducible FA of approximately $90 \%$ was obtained, showing the robustness of the FA determination (Table 1).

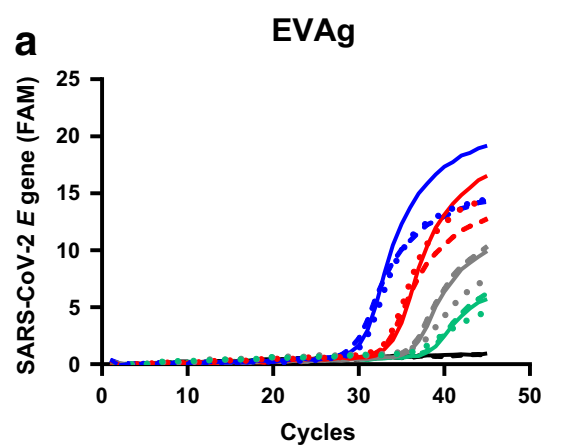

Fig. 2 Real-time amplification curves of the $E$ gene RT-PCR reference assay tested on the EVAg standard. The reference assay was described previously [2]. a EVAg dilution series with 5-5000 SARS-CoV-2 copies/reaction diluted in water. The continuous lines represent the reference assay in $25 \mu \mathrm{L}$ reaction volume $(n=1)$, the interrupted lines

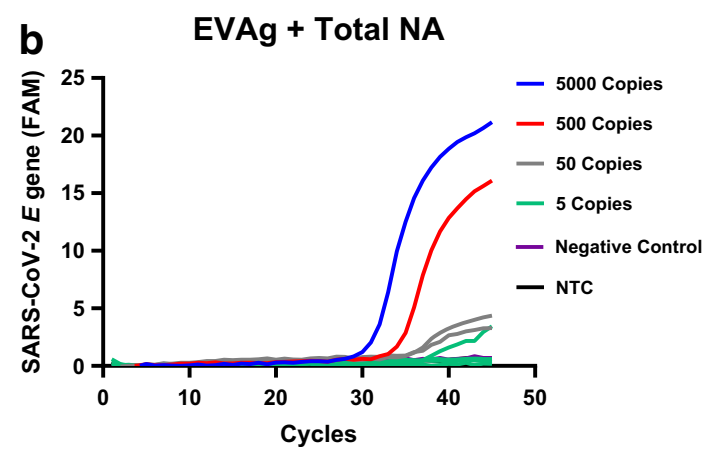

represent the reference assay in $10 \mu \mathrm{L}$ reaction volume $(n=1)$, and the dotted lines represent the $E$-GUSB duplex RT-PCR assay $(n=1)$. b EVAg dilution series in total NA extract from a Covid-19-negative patient tested with the RT-PCR assay. For 500-5000 copies/reaction $(n=1)$, for 50 copies/reaction $(n=2)$, for 5 copies/reaction $(n=4)$ 
Fig. 3 Real-time amplification curves of the $E$ gene reference and the $E-G U S B$ duplex assay tested on the EDx standard. a, c EDx dilution series with $2.5-1000$ SARS-CoV-2 copies/reaction diluted in water. $\mathbf{b}, \mathbf{d}$ EDx dilution series in total NA extract of a Covid-19-negative patient. The dotted lines represent the $E$ gene reference assay [2]. *EDx dilution in water. For $10-1000$ copies/reaction $(n=2), 2.5-5$ copies/reaction $(n=4)$
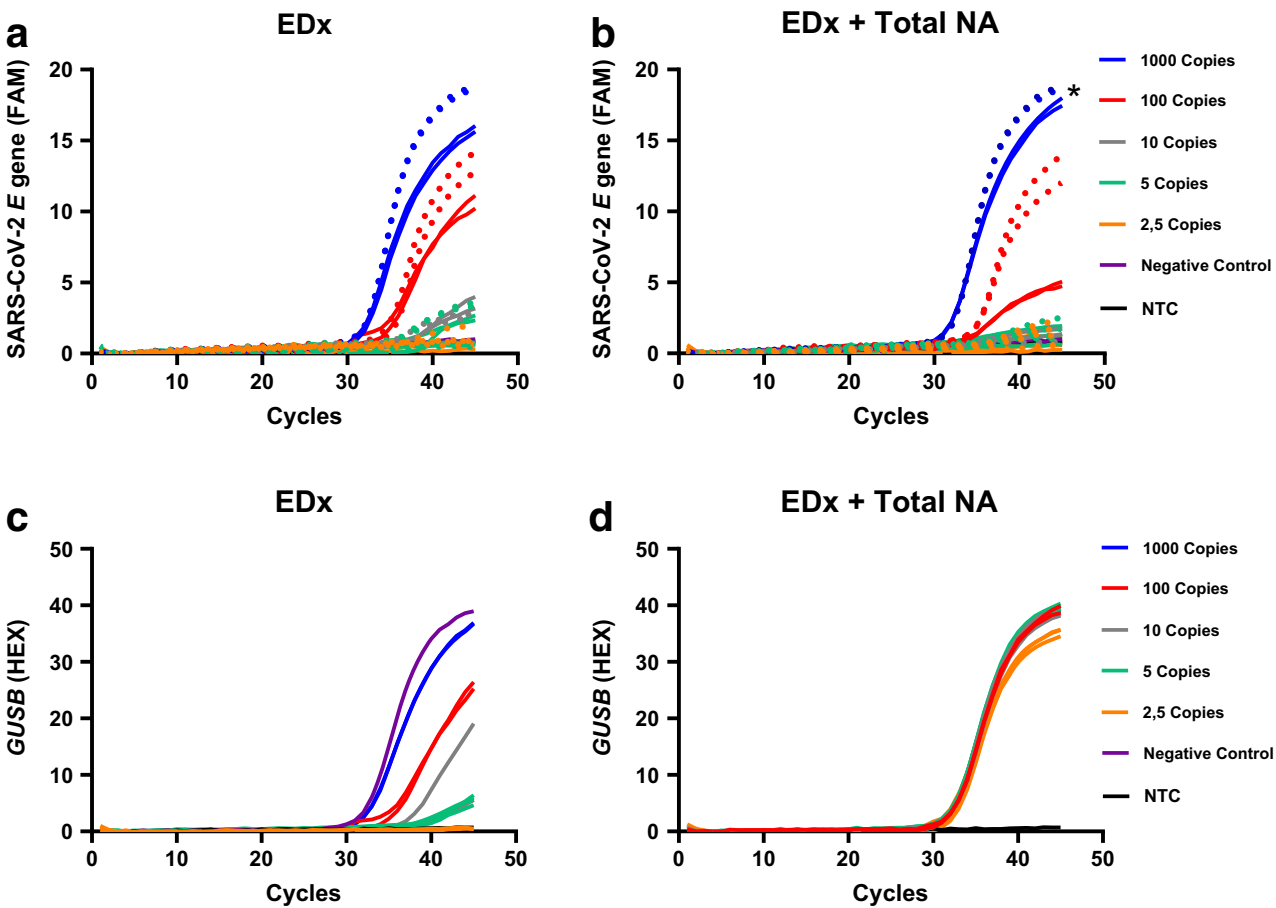

For the EDx standard dilution series in total NA extract, obtained from Covid-19-negative patients, a GUSB mRNA concentration of at least 100 copies per reaction was detected
(Table 2). In this background of total NA, down to 5 SARSCoV-2 copies per reaction can be detected, but the limit of quantification (LoQ) is estimated to be 10 copies per reaction,

Table 2 EDx dilution series tested using the SARS-CoV-2 RT-PCR $E$ gene reference*, $E$-GUSB duplex, and RT-ddPCR multiplex assay

\begin{tabular}{|c|c|c|c|c|c|c|c|c|c|c|}
\hline \multirow{4}{*}{$\begin{array}{l}\text { EDx standard } \\
\text { (Cp/reaction) }\end{array}$} & \multicolumn{5}{|c|}{ RT-PCR (Ct value) } & \multicolumn{5}{|c|}{ RT-ddPCR (copies/reaction) } \\
\hline & \multirow{2}{*}{\multicolumn{2}{|c|}{$\frac{E \text { Simplex }}{\text { SARS-CoV-2 }}$}} & \multicolumn{3}{|c|}{ E-GUSB Duplex } & & & & & \\
\hline & & & \multicolumn{2}{|c|}{ SARS-CoV-2 } & \multirow[t]{2}{*}{$G U S B$} & \multicolumn{2}{|l|}{ SARS-CoV-2 } & \multirow[t]{2}{*}{ Rpp30 } & \multirow[t]{2}{*}{ GUSB } & \multirow[t]{2}{*}{ FA $(\%)$} \\
\hline & Water & Total NA & Water & Total & & Water & Total NA & & & \\
\hline 1000 & 31.7 & NA & 31.3 & NA & NA & $1098(1004-1192)$ & NA & NA & NA & NA \\
\hline 1000 & 31.7 & NA & 31.6 & NA & NA & $1002(916-1090)$ & NA & NA & NA & NA \\
\hline 100 & 34.2 & 34.2 & 34.4 & 33.1 & 32.2 & $108(80-140)$ & $94(70-124)$ & $4531(4338-4726)$ & $155(123-192)$ & 38 \\
\hline 100 & 34.7 & 34.4 & 34.6 & 33.6 & 32.2 & $114(86-150)$ & $96(74-124)$ & $4343(4164-4523)$ & $115(89-145)$ & 45 \\
\hline 10 & 34.1 & ND & 36.3 & ND & 32.2 & $20(10-34)$ & $5.6(1.4-14.8)$ & $5028(4830-5229)$ & $160(128-196)$ & 3 \\
\hline 10 & 34.5 & ND & 36.8 & ND & 32.1 & $12(4-24)$ & $18(8-32)$ & $4990(4788-5194)$ & $152(120-188)$ & 10 \\
\hline 5 & ND & ND & ND & ND & 31.9 & $9(2.6-21)$ & $9(3.2-19.6)$ & $5254(5054-5457)$ & $112(86-142)$ & 7 \\
\hline 5 & ND & ND & 37.3 & ND & 32.0 & $2.4(0.2-11.8)$ & $3.2(0.4-10)$ & $4942(4761-5125)$ & $129(103-159)$ & 2 \\
\hline 5 & 35.2 & 35.6 & 36.9 & ND & 32.0 & $7.6(2.2-17.8)$ & $11.6(4.8-22.4)$ & $4818(4635-5002)$ & $124(98-154)$ & 9 \\
\hline 5 & 35.2 & ND & ND & $\mathrm{ND}$ & 32.0 & $5.6(1.4-14.8)$ & $10.2(3.6-22.4)$ & $5256(5041-5472)$ & $148(117-186)$ & 6 \\
\hline 2.5 & ND & ND & ND & $\mathrm{ND}$ & 32.1 & $\mathrm{ND}$ & $\mathrm{ND}$ & $4820(4640-5020)$ & $122(96-154)$ & \\
\hline 2.5 & ND & ND & ND & $\mathrm{ND}$ & 32.2 & $\mathrm{ND}$ & $\mathrm{ND}$ & $5160(4960-5380)$ & $106(80-138)$ & \\
\hline 2.5 & 35.3 & ND & ND & ND & 32.0 & ND & $3.4(0.6-11)$ & $4840(4660-5040)$ & $112(86-142)$ & 3 \\
\hline 2.5 & ND & 35.6 & ND & ND & 32.3 & ND & ND & $4860(4660-5060)$ & $112(86-144)$ & \\
\hline
\end{tabular}

$N A$ not applicable, $N D$ not detected, $F A$ fractional abundance of viral RNA calculated with respect to the GUSB concentration

*Gold standard assay [2] 


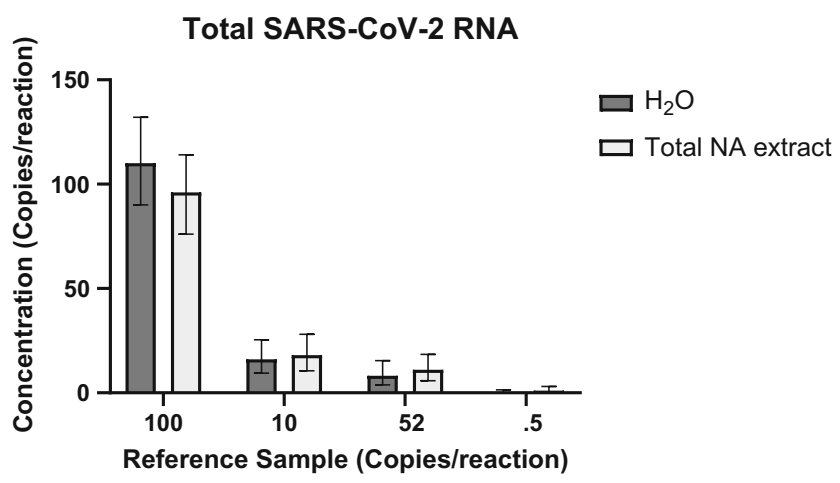

Fig. 4 Dilution series of the EDx standard diluted in water or total NA extract of a Covid-19-negative nasopharyngeal swab tested with the SARS-CoV-2 RT-ddPCR multiplex assay. For 10-100 copies/reaction $(n=2), 2.5-5$ copies/reaction $(n=4)$

as the FA obtained with 5 or 10 SARS-CoV-2 copies per reaction overlaps (Table 2).

For 5 Covid-19-negative patient samples, the GUSB mRNA concentration was determined individually (Fig. 1b; Table 1). Remarkably, for one sample, a GUSB mRNA concentration of just 14 copies per reaction, so far below 100 copies per reaction, was found, implying poor sample collection or poor reverse transcription that could have resulted in a false negative result.

\section{Discussion}

A novel RT-ddPCR multiplex assay was developed targeting three different genes of the SARS-CoV-2 virus. As the SARS$\mathrm{CoV}-2$ genome evolves rapidly $[8,9]$, it is of interest to screen multiple targets simultaneously to avoid possible mismatches of primers and probes, which could lead to false negative results [11]. The SARS-CoV-2 RT-ddPCR multiplex assay also includes a patient-derived NA extraction control and a reverse transcriptase control to ensure adequate sample and assay quality required for reliable virus detection.

While reverse transcriptase RT-PCR is still the gold standard, the findings in the present study indicate that the assay sensitivity of the RT-PCR assay is reduced due to background NA from the patient sample. By contrast, the sensitivity of the RT-ddPCR multiplex assay was not affected by background NA and is more sensitive than the gold standard reverse transcriptase RT-PCR [4-7] in the clinical setting.

As ddPCR enables absolute quantification, not only the viral RNA can be quantified but also the GUSB mRNA, which can be used to set validity criteria and to ensure reliable analysis, as false negative results may occur due to poor sample quality as a result of inappropriate sample collection, handling, or transportation [12]. For the SARS-CoV-2 RTddPCR developed in this study, 5 copies of viral RNA are reliably detectable and 10 copies viral RNA copies are reliably quantifiable in a background of at least 100 GUSB mRNA copies.

By quantification of SARS-CoV-2 relative to patientderived GUSB mRNA, the fractional abundance of the viral loads of different samples can be compared. This could be used to gain insights in the relation between viral load and infectivity, which is at this moment unclear [13-16].

Together, this study presents a sensitive one-step RTddPCR multiplex assay that allows for reliable detection and quantification of SARS-CoV-2 viral RNA with respect to patient-derived mRNA of a house-keeping gene, what could be used for triage and enables disease monitoring of Covid-19 patients.

Acknowledgments We thank the Institut für Virologie Charité, Universitätsmedizin Berlin for providing the EVAg standard and BioRad Laboratories for providing reagents needed for the ddPCR experiments.

Authors' contributions RdK: Conducted experiments, conceptualized the laboratory work, wrote the manuscript. MB: Conducted experiments, contributed to manuscript. VS: Contributed to manuscript. BD: Planned experiments, conceptualized the laboratory work, conceptualized the overall study, wrote the manuscript.

Data availability Upon request.

\section{Compliance with ethical standards}

Conflict of interest Not applicable.

Ethics approval Not applicable.

Consent to participate Not applicable.

Code availability Not applicable.

Open Access This article is licensed under a Creative Commons Attribution 4.0 International License, which permits use, sharing, adaptation, distribution and reproduction in any medium or format, as long as you give appropriate credit to the original author(s) and the source, provide a link to the Creative Commons licence, and indicate if changes were made. The images or other third party material in this article are included in the article's Creative Commons licence, unless indicated otherwise in a credit line to the material. If material is not included in the article's Creative Commons licence and your intended use is not permitted by statutory regulation or exceeds the permitted use, you will need to obtain permission directly from the copyright holder. To view a copy of this licence, visit http://creativecommons.org/licenses/by/4.0/.

\section{References}

1. COVID-19 Dashboard by the Center for Systems Science and Engineering (CSSE) at Johns Hopkins University (JHU). https:// coronavirus.jhu.edu/map.html. Accessed 13 Oct 2020

2. Corman VM et al (2020) Detection of 2019 novel coronavirus (2019-nCoV) by real-time RT-PCR. Euro Surveill Bull Eur Sur 
Mal Transm Eur Commun Dis Bull 25(3). https://doi.org/10.2807/ 1560-7917.ES.2020.25.3.2000045

3. Chu DKW et al (2020) Molecular diagnosis of a novel coronavirus (2019-nCoV) causing an outbreak of pneumonia. Clin Chem 66(4): 549-555. https://doi.org/10.1093/clinchem/hvaa029

4. Suo T et al (2020) ddPCR: a more accurate tool for SARS-CoV-2 detection in low viral load specimens. Emerg Microbes Infect 1-30. https://doi.org/10.1080/22221751.2020.1772678

5. Yu F et al (2020) Quantitative detection and viral load analysis of SARS-CoV-2 in infected patients. Clin Infect Dis Off Publ Infect Dis Soc Am. https://doi.org/10.1093/cid/ciaa345

6. Dong L et al (2020) Highly accurate and sensitive diagnostic detection of SARS-CoV-2 by digital PCR'. Public and Global Health, preprint. https://doi.org/10.1101/2020.03.14.20036129

7. Falzone $\mathrm{L}$ et al (2020) Sensitivity assessment of droplet digital PCR for SARS-CoV-2 detection. Int J Mol Med 46(3):957-964. https:// doi.org/10.3892/ijmm.2020.4673

8. Khailany RA, Safdar M, en Ozaslan M (2020) Genomic characterization of a novel SARS-CoV-2. Gene Rep 100682. https://doi.org/ 10.1016/j.genrep.2020.100682

9. Pachetti M et al (2020) Emerging SARS-CoV-2 mutation hot spots include a novel RNA-dependent-RNA polymerase variant. J Transl Med 18(1):179. https://doi.org/10.1186/s12967-020-02344-6

10. Younes $\mathrm{N}$ et al (2020) Challenges in laboratory diagnosis of the novel coronavirus SARS-CoV-2. Viruses 12(6):26. https://doi.org/ $10.3390 / \mathrm{v} 12060582$
11. Muenchhoff M et al (2020) Multicentre comparison of quantitative PCR-based assays to detect SARS-CoV-2, Germany, March 2020. Euro Surveill Bull Eur Sur Mal Transm Eur Commun Dis Bull 25: 24. https://doi.org/10.2807/1560-7917.ES.2020.25.24.2001057

12. Tahamtan A, Ardebili A (2020) Real-time RT-PCR in COVID-19 detection: issues affecting the results. Expert Rev Mol Diagn 20(5): 453-454. https://doi.org/10.1080/14737159.2020.1757437

13. Widders A, Broom A, Broom J (2020) SARS-CoV-2: the viral shedding vs infectivity dilemma. Infect Dis Health 25(3):210 215. https://doi.org/10.1016/j.idh.2020.05.002

14. La Scola B et al (2020) Viral RNA load as determined by cell culture as a management tool for discharge of SARS-CoV-2 patients from infectious disease wards. Eur J Clin Microbiol Infect Dis Off Publ Eur Soc Clin Microbiol 39(6):1059-1061. https://doi.org/ 10.1007/s10096-020-03913-9

15. Zou L et al (2020) SARS-CoV-2 viral load in upper respiratory specimens of infected patients. N Engl J Med 382(12):11771179. https://doi.org/10.1056/NEJMc2001737

16. Zhou $\mathrm{R}$ et al (2020) Viral dynamics in asymptomatic patients with COVID-19. Int J Infect Dis IJID Off Publ Int Soc Infect Dis 96: 288-290. https://doi.org/10.1016/j.jiid.2020.05.030

Publisher's note Springer Nature remains neutral with regard to jurisdictional claims in published maps and institutional affiliations. 